\title{
Application of Common Examples in Engineering Graphics Teaching
}

\author{
Ruiting Tong \\ School of Mechanical Engineering \\ Northwestern Polytechnical University \\ Xi'an, P. R. China \\ e-mail: tongruiting@nwpu.edu.cn
}

\begin{abstract}
Based on the current situation of engineering graphics teaching, some problems are presented. The characteristics of engineering graphics teaching are analyzed, and applications of common examples are developed and shown in this paper. Several common examples corresponding to the contents of engineering graphics are given. Common examples can help the students to understand the engineering graphics definition and make them interest in engineering graphics. Applications of common examples and the guide of the teacher can cultivate the students' creative thinking. Employments of scientific research are discussed finally. Some related scientific research can be used to improve the teaching effects.
\end{abstract}

Keywords-common example; engineering graphics teaching; scientific research; creative thinking; teaching effects

\section{INTRODUCTION}

To adapt the fast development of the society, many universities update their training plans, and more and more kinds of curriculum are presented. The teaching hours of every curriculum are less due to the limit of the total teaching hours, and the reduced teaching hours will result in less teaching contents[1]. For example, in the mechanical drawing course of non-mechanical major, some contents such as partial intersecting, truncation of oblique plane and its development, axonometric drawing, comprehensive mapping method, geometric tolerance, parts measurement, et al. are deleted gradually. Although some contents of computer drawing are added to mechanical drawing, the total class hours are less. Besides, the teachers hope that the students master all the teaching contents, and the individual differences are ignored. Furthermore, the students' individual development and their creative thinking are inhibited, and they are not interested in engineering graphics to result in limited knowledge range further. According to statistics, $95 \%$ of the students do not read extracurricular books about engineering graphics or even other teaching materials. Generally, universities will evaluate the students and the teachers by students' examination results, which results in the high unity between training plans and examination contents. Therefore, the students get narrow knowledge ranges, and the teachers' teaching level is enhanced slowly, which is harmful to both the teachers and students.

From the analysis above, engineering graphics teaching meets the following problems: (i) How to improve the teaching effects under the condition of less teaching hours;

(ii) How to enhance the interests of the students when teaching the basic knowledge;

(iii) How to help the students understand the knowledge more deeply;

(iv) How to guide the students to perform creative design based on the available knowledge.

Many researchers tried lots of strategies to solve above problems in recent ten years. Tong et al.[2] described various viewpoints for introducing 3D modeling into engineering graphics curriculum from experts, graphic educators in home and abroad. Duan et al.[3] performed teaching reform by the employment of 3D modeling, in which 3D and 2D models had the same position. Kang[4] presented a teaching method which combined CAI courseware with $3 \mathrm{D}$ CAD software to enhance creative thinking of students. In Ref. [5], the training of creative talented person was considered to be the last aim of education reform. The accurate fixed position, outstanding the special features, optimizing the construction, insisting on putting the education and teaching quality should also be highlighted. Chen et al.[6] presented engineering graphics teaching system based on configuration design, in which configuration design was used to train thinking mode about engineering graphics. Lei et al.[7] organized the mechanical drawing course based on product manufacturing process, which could help to enhance students' interests. Feng[8] analyzed engineering graphics education in U.S. universities, and pointed out the characteristics: (i) combining graphic contents with design intellection; (ii) applying all kinds of ways to express the design; (iii) requiring expressive skill and self-learning ability for students. Luo et al.[9] gave some opinions on the training and evaluation of students' creative thinking in graphics education. They advised that graphics education should highlight the machine design based on the reform thinking. Yang et al.[10] suggested building the whole procedure education system of engineering graphics for the practice and innovation. However, the courses of graphics engineering are usually arranged in Grade one in most of the universities, and the students do not have enough knowledge about mechanical design or product manufacturing. Furthermore, the freshmen are not familiar with 3D modeling, and the introducing of 3D modeling may not obtain the expected results. 
In view of these, the method of introducing common examples to engineering graphics teaching is presented in this paper. According to these simple examples, the students can deeply understand the engineering background of the knowledge. Furthermore, the common examples will help to enhance the students' interest on engineering graphics, and improve the effects of engineering graphics teaching. Finally, the examples of scientific researches are introduced in the engineering graphics teaching, which can cultivate the students' creative intellection.

\section{ENGINEERING GRAPHICS PROBLEMS AND THEIR CORRESPONDING COMMON EXAMPLES}

In engineering graphics teaching, many definition and methods are difficult to understand for a freshman, so the common examples are chosen based on the basic necessities of life. Then, the students will surprise that they are surrounded by the knowledge of engineering graphics, and they will interest in engineering graphics further.

\section{A. Mutually Intersecting Between Two Cylinders}
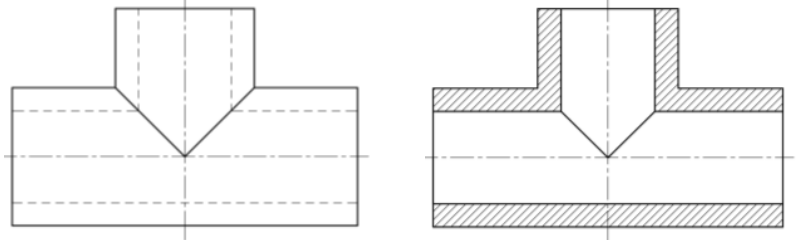

(a) Two same cylinders
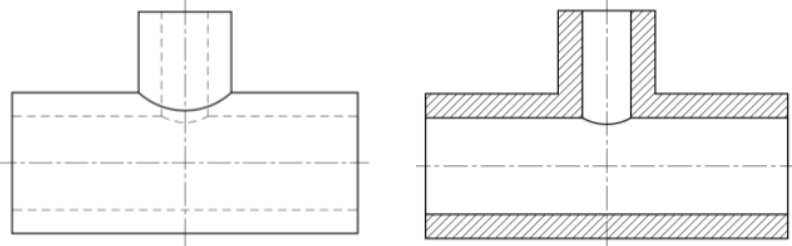

(b) Two different cylinders

Figure 1. Mutually intersecting between two cylinders.

Mutually intersecting between two cylinders is widely known or used in the cases when one wants to connect two perpendicular pipes, and the corresponding example is a tee. Fig. 1 shows the projections and cutaway views for the mutually intersecting between two same cylinders or two different cylinders. These components can be seen in the classrooms in the north of China where the radiators are widely used to heat the room. So, it is convenient to show this common example to the students, and the teacher can also ask the students to look for other examples around them.

\section{B. Left Hand Thread}

For the freshmen, they have the impression of right hand threads which can be seen everywhere, but what is the use of left hand thread? There are almost no one knowing that. Therefore, if the teacher only teaches the students the definition of left hand thread, they will forget it soon, and the common examples should be more important. The teacher can ask the students a question: How do the two parts of the radiator connect together? Left hand thread is used on one side and right hand thread is used on another side, and the two parts are connected tightly. However, this example can not be seen because the threads are covered when they insert into the parts. The left hand threads are also used when one wants to avoid thread loosening. A common example is soymilk machine. When the electromotor rotates, the thread will be loosened if one use right hand thread, and the left hand thread should be used here to ensure stable operation. Soymilk machine is so widely used in students' families that most of the students have operated soymilk machine by themselves, so this example is useful to help the students to understand the left hand thread. Then, the teacher can leave the students several minutes to discuss some other common examples. In my class, some students find that the footboards of the bikes should use the left hand thread to avoid loosening. According their experiences, they also point out that the nut often disappears if the right hand thread is used in the position of the left hand thread. From the communication and discussion, some students find that engineering graphics is so interesting, and "Double Effect" will be shown in teaching.

\section{The Definition of Start of Thread}

The teacher uses teaching aid to show the students two threads with the same radius, the same pitch, the same profile of teeth, and the same thread direction, but the liner speeds of the two nuts are different when one rotates the screw. Then the definition of start of thread is introduced to the students, and also one can introduce the definition of lead. What is the common example?

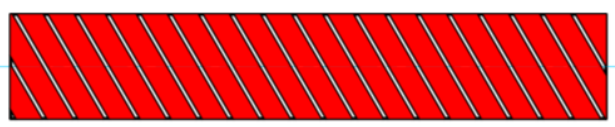

(a) One start

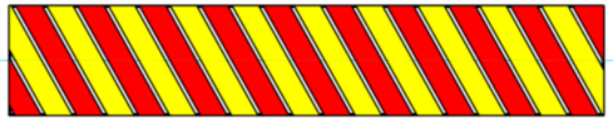

(b) Two starts

Figure 2. Common example of the definition of start.

It is well known that the campus is decorated splendidly when Chinese festivals is coming. In classroom, the fluorescent tubes will be winded by color bars. If one winds the fluorescent tubes by one color, it is considered that the start of "the thread" is one, as shown in Fig. 2(a). If one winds the fluorescent tubes by two colors, it is considered that the starts of "the thread" is two, as shown in Fig. 2(b). When the screw rotates $360^{\circ}$, the displacement of the nut is defined as lead. Compared Figs. 2(a) and 2(b), one can find that the lead depends on the pitch and starts. Then, the teacher can introduce the characteristics of the single thread or multiple thread. 


\section{Other Examples}

Before the students make the assemble drawing, the teacher will show them an assemble drawing of a stop valve as an example. The working principle of the stop valve should be introduced firstly, and the corresponding common example can be a faucet or a hydrant. The working principle will also help the students to make detail drawings, so a common example should be more important. In assemble drawing, the ribbed slab is always used to enhance the structural stiffness. The common example can be the base of street lamp which has four ribbed slabs. The students see street lamps everyday, and most of them pay attention to the ribbed slabs but they do not know the application of that. Then, lots of applications are found out by the students and better effects can be obtained in teaching.

\section{EMPLOYMENT OF SCIENTIFIC RESEARCH}

With the development of university education, scientific research plays more and more important role in engineering graphics. Jiao et al.[11] analyzed the current education situation and the developing tendency in the future. They also discussed the relationship between engineering graphics education and mechanical drawing. Furthermore, in Ref. [12], they pointed out that the teachers should do some researches besides the teaching in class, and the researches could help to improve the teaching effects. There are several examples can be used in the mechanical drawing course.

\section{A. The Development of Gears}

Most of the students know spur gears(shown in Fig. 3(a)), and the gears are used to transmit torque. Is there any way to improve the gears if one wants to enhance the ability to transmit torque? The answer is increasing the width of the gears. And then, helical gears(shown in Fig. 3(b)) can be introduced to the students. One can use helical gears to enhance the transmission ability, while the width of the gear is not increased. In some cases, the weight of mechanical components is critical, and increasing the width of gear means increasing the weight. What will be happened when we combine two helical gears together? That is the birth of herringbone gear(shown in Fig. 3(c)) which can be used to transmit much higher torque and widely used in ships. The logo of Citroen is two teeth of the herringbone gear. The development of spur gears, helical gears and herringbone gears will help the students to analyze problems divergently. Furthermore, the teacher can introduce arc gear and double circular-arc herringbone gear to further show the students common examples.

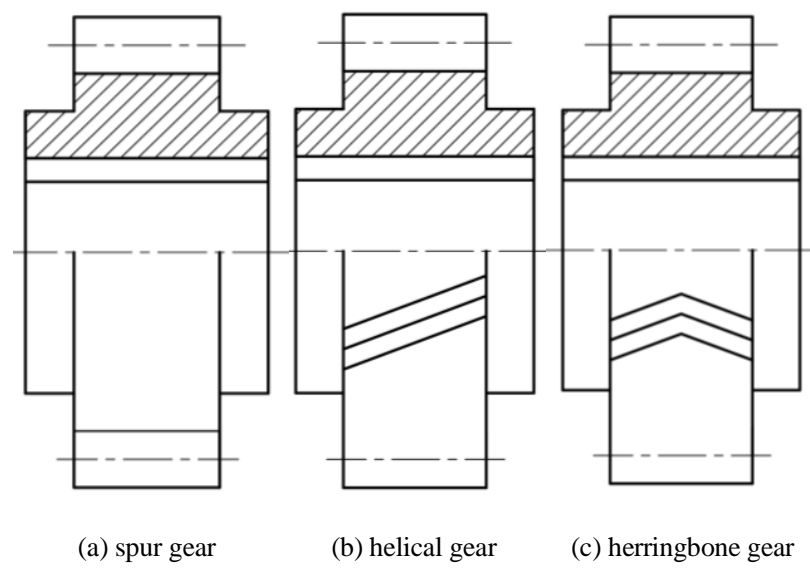

Figure 3. The development of gears.

When two gears are assembled, they can tranmit torque. What should we do if we want to transmit more higher torque? The answer is planetary gear which is shown in Fig. 4. Several gears are used around the sun gear in a planetary gear to enhance the transmission ability.

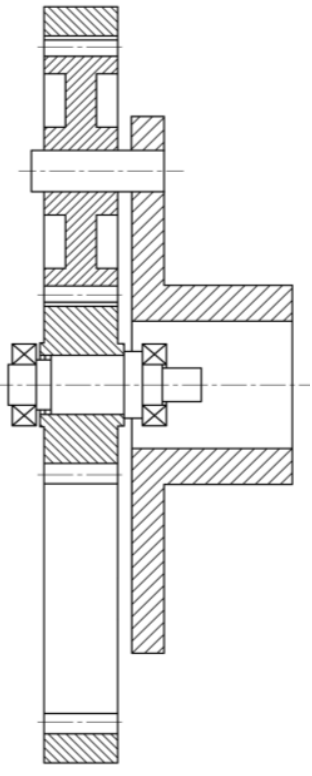

Figure 4. Planetary gear.

The gears shown above are all used to transmit parallel torque, and the axes of two gears are parallel. Could we make the axes perpendicular to each other? If one wants to transmit perpendicular torque, bevel gears should be used, as shown in Fig.5(a), and the axes of the two gears are perpendicular. Then, another mechanism called worm gears can be introduced to transmit perpendicular torque, and the work principle of which should also be introduced. Although the content of gear is simple, the development of gears can be used to cultivate students' creative thinking. 


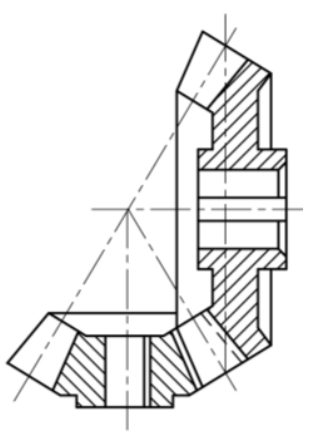

(a) bevel gears

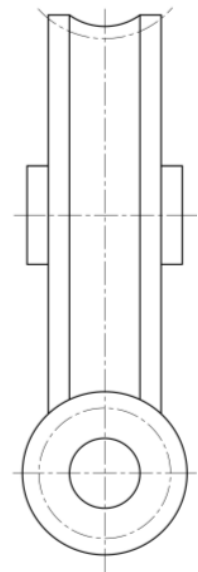

(b) worm gears
Figure 5. Mechanisms used to transmit perpendicular torque.

\section{B. Geometric Tolerance}

The content of geometric tolerance is deleted from the mechanical drawing course of non-mechanical major, but the teacher should introduce geometric tolerance briefly. My major is nano-friction, and I introduce the flatness from the view of nanoscale plane, as shown in Fig. 6. The ideal flat plane consists of many atoms, and atoms on the surface of the plane are arranged in order. It is well known that atoms are spheres, so the surface of the ideal flat plane consists of many hemispheres actually. Then, we can conclude that there is no flat plane in the universe, and the definition of flatness can be introduced now.

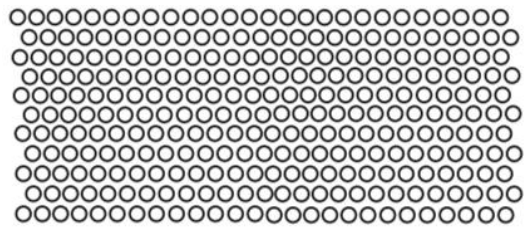

Figure 6. Ideal flat plane.

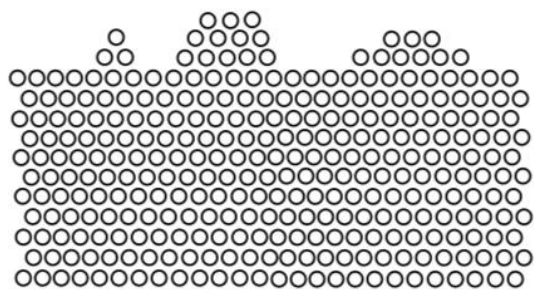

Figure 7. Nanoscale rough surface.

Furthermore, the roughness of the surface can be also introduced through Fig. 7 which shows the nanoscale rough surface. If one does not do some related scientific researches, reading more corresponding papers could also help to improve the teaching effects.

\section{CONCLUSION}

According to the characteristics of engineering graphics teaching, applications of common examples are presented in this paper. Several common examples corresponding to the contents of engineering graphics are given. Employments of scientific research are discussed finally. Some conclusions are drawn as follows:

A. Common examples can help the students to understand the engineering graphics definition and make them interest in engineering graphics;

B. Applications of common examples and the guide of the teacher can cultivate the students' creative thinking;

C. Employments of related scientific research can be used to improve the teaching effects.

\section{ACKNOWLEDGMENT}

Mr. Tong Ruiting thanks professors Sun Genzheng, Gao Mantun, Li Xiqin, Zang Hongqi, and Ye Jun for their help in teaching and beneficial discussion.

Supported by the 111 Project (Grant No. B13044).

\section{REFERENCES}

[1] Y. Y. Liu, S. R. Qu, Z. S. Lei, M. T. Gao, "Discussion of graphic teaching," J. Northwestern Polytechnical Univ. (Social Sciences) vol. 21, pp. 81-83, June 2001. (in Chinese)

[2] B. S. Tong, S. J. Yi, X. H. Xu, "Investigation and consideration of introducing $3 \mathrm{D}$ modeling into engineering graphics curriculum in China,” J. Eng. Graphics. vol. 26, pp. 130-135, August 2005. (in Chinese)

[3] L. W. Duan, S. Liu, "Scanning to the far, beginning from the detail- talking about the teaching reform of engineering graphics for nonmechanical major," J. Eng. Graphics. vol. 29, pp. 127-132, December 2008. (in Chinese)

[4] L. Kang, "Practice of engineering graphics teaching based on 3D CAD software," J. Eng. Graphics. vol. 28, pp. 152-156, December 2007. (in Chinese)

[5] X. Mao, Y. Huang, "Some thinking about the development of graphics education of our country," J. Eng. Graphics. vol. 25, pp. 96100, June 2004. (in Chinese)

[6] J. C. Chen, C. K. Chen, X. X. Deng, L. Liu, "Discussion of engineering graphics teaching system based on configuration design," J. Eng. Graphics. vol. 27, pp. 130-132, Octobor, 2006. (in Chinese)

[7] Z. S. Lei, H. Q. Zang, M. T. Gao, "Performing mechanical drawing teaching based on manufacture process of products," J. Northwestern Polytechnical Univ. (Social Sciences) vol. 22, pp. 93-95, December 2002. (in Chinese)

[8] J. Feng, "Analysis on engineering graphics education in U.S. universities," J. Eng. Graphics. vol. 29, pp. 139-144, June 2008. (in Chinese)

[9] A. L. Luo, S. C. Zhang, M. X. Xu, M. Zheng, "On the training and evaluation of student's creative thinking in graphics education," J. Eng. Graphics. vol. 21, pp. 105-108, August 2000. (in Chinese)

[10] W. T. Yang, Y. Li, F. P. Huang, A. P. Zhang, Z. L. Han, K. Q. Dong, "Study on the whole procedure education system of engineering graphics for the practice and innovation," J. Eng. Graphics. vol. 27, pp. 137-141, October 2006. (in Chinese) 
[11] Y. H. Jiao, T. Zhang, J. Chen, G. Y. Dong, "The investigation and research on the current education situation in universities in China," J. Eng. Graphics. vol. 25, pp. 125-130, August 2004. (in Chinese)
[12] Y. H. Jiao, T. Zhang, J. Chen, "The investigation and research on the current education situation in universities in China," J. Eng. Graphics. vol. 27, pp. 111-115, December 2006. (in Chinese) 